\title{
Hombres y mujeres del agua: adaptación y transformación del medio en la cultura anfibia
}

\author{
Men and women of water: Adaptation and transformation \\ of the environment in the amphibious culture
}

\author{
Donaldo Sierra Chávez, sierradonaldo@gmail.com \\ Universidad de Córdoba, Colombia
}

\section{Resumen}

Esta investigación muestra cómo los habitantes de La Mojana sucreña, en el norte de Colombia, viven, estacionalmente, bajo las inclemencias de las inundaciones. Para adaptarse a esta situación han modificado su estilo de vida, llevando así una supervivencia catalogada como anfibia. La geografía de esta región se pone de manifiesto por los cambios que el hombre hace a un medio físico, que por lo general se ensaña con él. Se tuvo en cuenta la observación directa y la apreciación de algunos integrantes de la comunidad de La Mojana (charlas, entrevistas, encuestas), con visitas de campo en dos épocas del año: sequía y lluvias. Se valoró especialmente cada una de las condiciones de vida y el accionar cultural de los habitantes. Lo que se pretendió entonces fue reconocer cómo el ser humano, bajo ciertas circunstancias de inundación, se ve en la necesidad de construir su propio espacio cultural para la convivencia, sobrevivencia y supervivencia.

Palabras claves: Adaptación, cultura anfibia, Mojana sucreña, percepción, transformación.

\section{Abstract}

The current research shows how the inhabitants of the Mojana sucreña, in the northern region of Colombia, seasonally live under the inclement flooding. In order to adapt themselves to this situation, people from this region have changed their lifestyle, carrying a survival life mode classified as amphibious. The geography of this region reveals itself because of the changes that the human being makes to the phyisical environment, which generaly preys on him. Direct observations and points of view of some members of La Mojarra community, including talks, interviews and surveys, were applied. Field visits during the dry and wet season were done, taking into consideration the living conditions and cultural behavior of the inhabitants. With this project, it was intended to recognize how the human being, under flooding circumstances, sees himself in the need of constructing his own cultural space for cohabitation and survival.

Keywords: Adaptation, amphibian culture, Mojana sucreña, perception, transformation. 


\section{Introducción}

Colombia es un país de muchas regiones que se encadenan como eslabones que forman un maravilloso ambiente habitable. Es reconocido a nivel internacional por poseer un medio físico y humano exuberante, dando con ello una diversidad de flora, fauna y cultura. Una de las regiones clave por su riqueza y recursos es el Caribe, que tiene desde costas y puertos abiertos al mundo, hasta montañas, picos elevados, lugares desérticos y vastos territorios de depresiones inundables. Cada uno de estos espacios posee características peculiares en lo geográfico y cultural que brindan al Caribe colombiano un incuestionable valor regional.

La región Caribe se encuentra ubicada en el norte de Colombia, dividida a su vez en subregiones de acuerdo a circunstancias físicas tales como la hidrografía, topografía y actividades antrópicas. Una de estas subregiones es llamada La Mojana, tierra de historias, de verdades, de alegrías y tristezas, de contrastes naturales y humanos, de connotaciones anfibias, fortalecidas por un genre de vie muy peculiar. La subregión de La Mojana colombiana se encuentra ubicada dentro de la Depresión Momposina y comprende cuatro departamentos: Antioquia, Bolívar, Sucre y Córdoba. Esta investigación se enfoca en La Mojana del departamento de Sucre y abarca los municipios de Majagual, Sucre y Guaranda, como se muestra en la Figura 1.

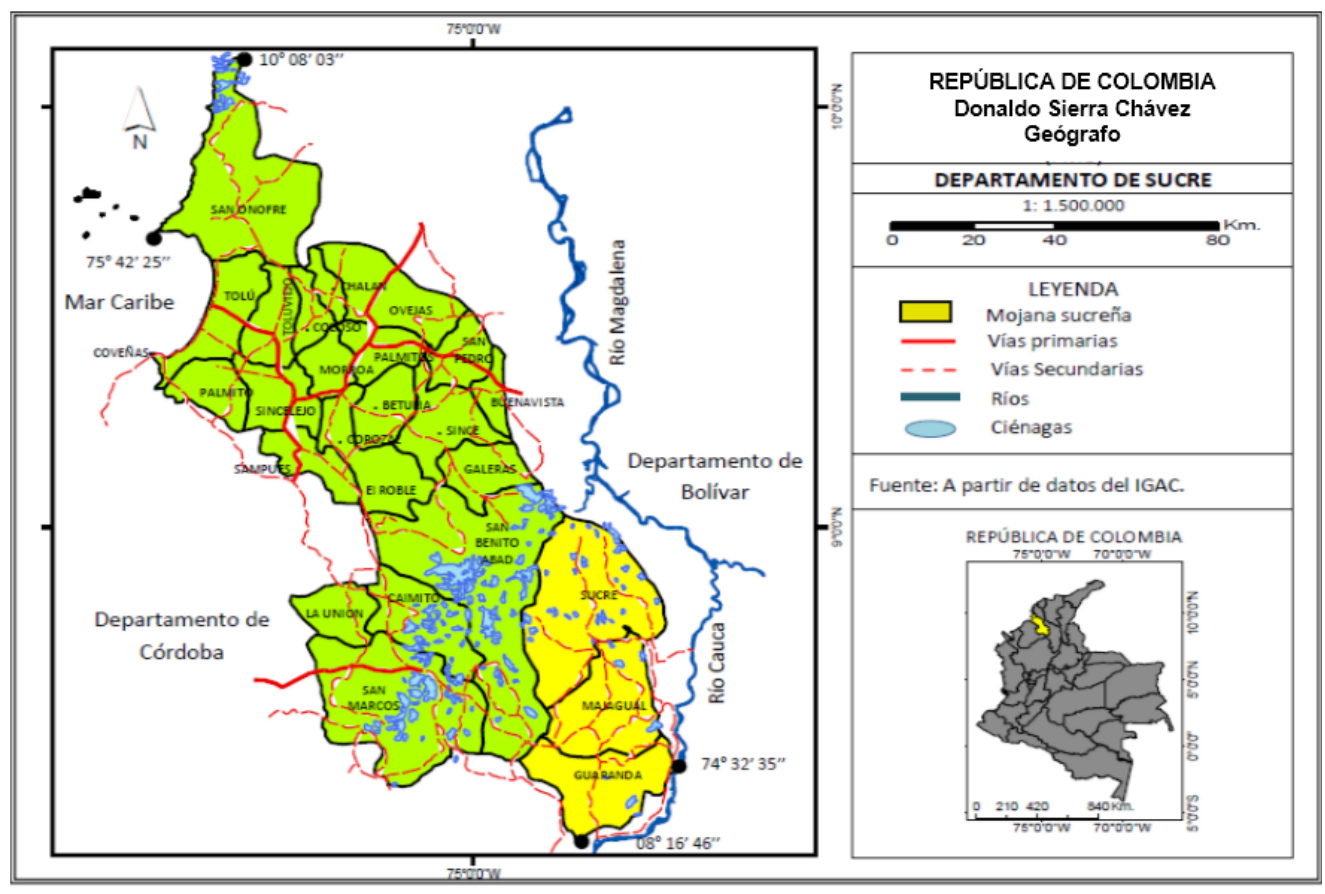

Figura 1. Mapa del departamento de Sucre (Elaboración propia a partir de datos del IGAC)

La Mojana sucreña se destaca por su riqueza hídrica, pues en ella se encuentra un número importante de ríos, caños, arroyos, ciénagas, humedales, entre otros. Cabe resaltar que el departamento de Sucre posee amplios espacios que hacen parte de La Mojana, ocupados en su mayoría por grandes extensiones de agua. Tal rasgo conlleva exuberante vegetación y diversidad de fauna, bondad que se traduce en sustento para su población en lo que concierne a las actividades agropecuarias y pesqueras. Sin embargo, cada vez que llega la época de lluvia se supera la capacidad de albergar agua en esta subregión, por lo que se producen inundaciones recurrentes.

La capacidad que muestra la cultura anfibia de La Mojana para adaptarse a un territorio 
alternativamente seco e inundado fue materia de investigación en este estudio, puesto que cada persona maneja ciertos rasgos de identidad que les dan fuerza, valor y representaciones de adaptabilidad, y que a pesar de sufrir las catástrofes de las inundaciones, continúan con la idea de vivir en ese lugar. De igual forma, la relación hombre-medio motiva patrones de transformación del paisaje. Entonces, investigar cómo y por qué se habita la región bajo las condiciones extremas que impone la naturaleza es promisorio, debido a que muestra un desafío sobrehumano en el imponente paisaje. Así, la investigación partió del siguiente interrogante: ¿Cuáles son los rasgos de identidad que definen la existencia de una cultura anfibia en La Mojana sucreña, específicamente en los municipios de Majagual, Sucre y Guaranda?

Para tratar de dar respuesta al interrogante anterior fue necesario centrarse en la vida del habitante de La Mojana sucreña, en su cultura y modo de vida. Para ello se analizaron los mecanismos de adaptación y transformación del medio desarrollados por las distintas comunidades que habitan esta área y que permiten explicar la interacción hombre-medio, lo que da lugar a un paisaje cultural caracterizado por el desarrollo de un modo de vida anfibio.

\section{Marco teórico}

Antes de la llegada de los colonizadores, la población indígena que habitaba lo que hoy es Colombia desarrolló a su manera el crecimiento y avances técnicos dirigidos a su quehacer diario. Los indígenas Zenú estaban supeditados a las condiciones ambientales de su hábitat pues dependían de las inundaciones o sequías estacionales, circunstancia que impactaba directamente en el crecimiento o decrecimiento de esa población.

Las primeras poblaciones de La Mojana sucreña se muestran como una majestuosa y laboriosa cultura indígena de rasgos interesantes con obras de admirar. Estos apelativos son sin duda alguna un indicativo de la cultura Zenú (o Zenúes), la cual dominaría un extenso territorio de llanuras y fuentes de agua, y tendrían acceso a diversos recursos naturales; sus labores y sistemas de asociación poblacional se ejercía en pequeñas aldeas.

Desde sus inicios, la población de La Mojana abraza fuertemente las condiciones que su medio le brinda, creando espacios para su supervivencia y configurando su territorio en función de lo que el ambiente le propone. De allí que construyan terraplenes, plataformas y canales artificiales (ver Figura 2). El paisaje del territorio Zenú se modifica con su sistema hidráulico, adaptaciones todas orientadas a su supervivencia.

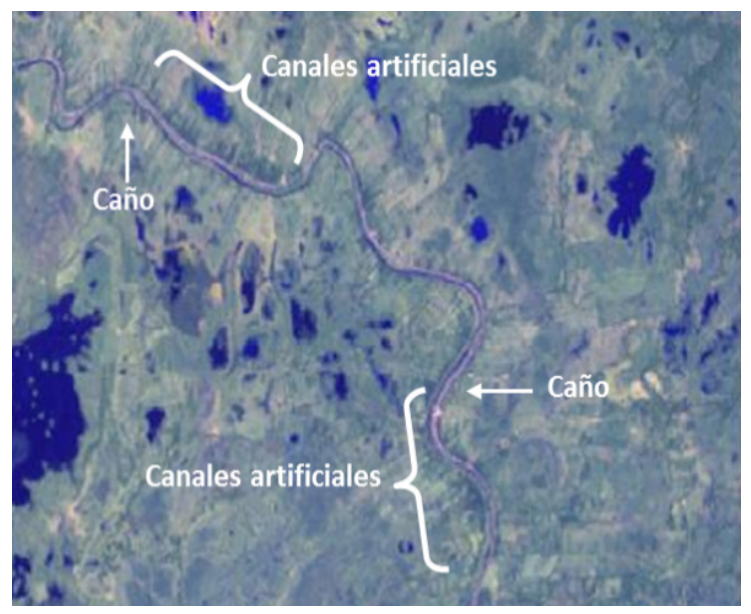

(a) Imagen Lansat (color falso 752 RGB). 


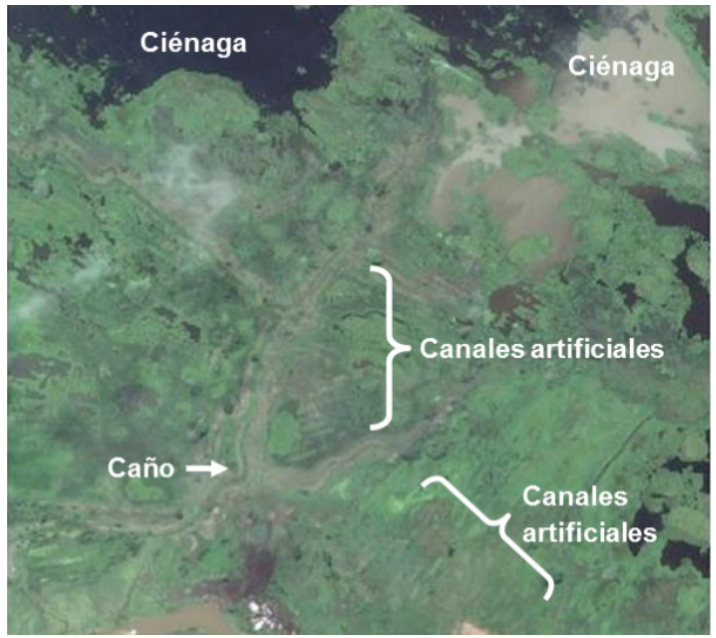

(b) Imagen Lansat (color natural 321 RGB).

Figura 2. Canales artificiales Zenú.

Se puede percibir, que desde la época indígena, se da el inicio de una vida de convivencia con el agua. Esta fue su motor y principal modelo de adopción y adaptación. Además del sistema hidráulico Zenú, también es de resaltar la gran riqueza de su orfebrería, alfarería, artesanía, así como de su material de uso doméstico, su división del trabajo y organización política (cacicazgos).

Todo lo vivido en el recorrido histórico no sería posible sin el reconocimiento del paisaje (Landschaft), pues este le brinda al ser humano herramientas, técnicas y métodos para adaptarse al medio. Su modificación es producto de la necesidad y seguridad de supervivencia. En ese sentido, Romero (2008), indica:

El paisaje es, sin lugar a dudas, uno de los elementos identitarios más excepcionales, uno de los patrimonios culturales más apreciados en las sociedades cultas y avanzadas de nuestro entorno. El paisaje es el resultado de una transformación colectiva de la naturaleza. Representa la proyección cultural de una sociedad en un espacio determinado y es, por ello mismo, un patrimonio que debe conservarse, admitiendo que es algo dinámico y en constante evolución (p. 183).

En el paisaje se distinguen dos elementos: el primero es un área física con todos sus recursos naturales; el segundo es visto como la impresión de los trabajos del ser humano sobre un área. En La Mojana se puede presenciar un paisaje de gran riqueza, de valores incalculables y con abundantes recursos, y además, con la significativa actividad humana en su transformación, es decir, la manifestación cultural.

Es preciso entonces, además de conocer el paisaje, tener nociones que contribuyan al valor de la cultura. El antropólogo Edward B. Tylor (1976), fue uno de los primeros en acuñar el concepto de cultura, entendida como «todo complejo que incluye conocimiento, creencia, arte, moral, derecho, costumbres y cualesquiera otras capacidades y hábitos adquiridos por el hombre como miembro de una sociedad» (p. 19). El ser humano se convierte así en un constructor, en un artista permanente de su cultura bajo las condiciones que le impone el medio. Aunque polisémico, el concepto de cultura puede definirse como la suma de rasgos de comportamientos y creencias aprendidas por los miembros de una sociedad.

Otros autores, como White (1949) y Steward (1972), citados por Nanda (1987), proyectan sus 
nociones de cultura desde el enfoque ecológico, generando un entramado estudio desde las respuestas del ser humano en el proceso de adaptación para la supervivencia. Al respecto, Nanda, expresa:

La teoría de White era que el desarrollo cultural procede mediante una creciente transformación eficiente de energía que a su vez lleva a un crecimiento poblacional, al incremento de la productividad y a la especialización económica (...) En la teoría multilinear de Julian Steward, las culturas son primariamente sistemas que evolucionaron como respuestas de adaptación a específicos ambientes naturales (p. 51).

Desde la perspectiva de estos dos antropólogos, White expone que es necesaria la evolución del ser humano en el ámbito cultural y que esta depende de las diferentes actividades cotidianas que aquel desarrolle; mientras que para Steward las formas de evolución son el resultado de las relaciones del ser humano con su entorno, es decir, las etapas culturales en la relación con el ambiente natural.

Para muchos antropólogos la ecología cultural estudia y sustenta que los patrones culturales son la respuesta a la adaptación del ser humano a su medio, y que a través de las dificultades que se presentan en el entorno es que se acrecienta la cultura. En La Mojana, los problemas que originan las inundaciones han dado fuerza y vitalidad a una comunidad muy bien llamada cultura anfibia, noción que se materializa en técnicas de supervivencia, instituciones, valores, normas, creencias y tradiciones muy particulares. Con relación a estas particularidades culturales que caracterizan a La Mojana,Fals Borda (2002b), advierte:

La cultura anfibia contiene elementos ideológicos y articula expresiones psicosociales, actitudes, prejuicios, supersticiones y leyendas que tiene que ver con los ríos, caños, barrancos, laderas, playones, ciénagas y selvas pluviales; incluye instituciones afectadas por la estructura ecológica y la base económica del trópico, como el poblamiento lineal por las corrientes de agua, las formas y medios de explotación de los recursos naturales, y algunas pautas especiales de tenencia de la tierra (p. 21).

\section{Adaptación}

Fortaleciendo el ámbito de la investigación y con los conceptos de paisaje y cultura, es preciso enfocarse mucho más en las apreciaciones de la adaptación. Antropológicamente, el concepto responde a las características usuales con que los individuos se hacen y dan respuesta a su medio. Según Barfield (2007), la adaptación involucra: «Cambios de la frecuencia de genes que le confieren una ventaja reproductiva a una población en un medio dado y cambios fisiológicos y socioculturales que aumentan la aptitud y el bienestar individual» (p. 1).

La adaptación es una respuesta producto del desarrollo humano ante un paisaje. Crece continua e irreversiblemente y se estimula ante los desafíos del medio. Todo ser vivo responde a su medio. La adaptación es, por así decirlo, un compromiso que potencializa e incita al progreso y a la competencia. En este orden de ideas, los pobladores de La Mojana no solo se adaptan al medio ambiente o paisaje, sino que se esfuerzan por cambiar el impacto del medio sobre ellos. Ya lo expone Harris (1968), cuando indica:

Tecnologías similares aplicadas a ambientes similares tienden a producir similares sistemas de trabajo, producción, distribución, etc.; esto a su vez produce similares agrupamientos sociales, los cuales justifican y coordinan sus actividades por medio de sistemas similares de valores y creencias (p. 4). 
Así pues, las actividades adaptativas producto del trabajo son insignes de cada comunidad. Es a través de las acciones del diario vivir que se fortalece y justifica el accionar cultural.

Los sistemas de trabajo son aceptados y acoplados dentro de un grupo, esto hace que la adaptación al ambiente genere los espacios necesarios para la supervivencia. Con la adaptación sobreviene un proceso de transformación que en el ámbito cultural se entiende como un cambio de forma o naturaleza de algún terreno, de tal suerte que el paisaje natural está siendo sometido a transformaciones por el ser humano, el cual utiliza los mecanismos y formas para usarlo, alterarlo o destruirlo. En palabras de Romero (2008):

Las sociedades humanas, a través de sus culturas, transforman los originarios paisajes naturales en paisajes culturales, caracterizados no solo por una determinada materialidad (formas de construcción, tipos de cultivos), sino también por la traslación al propio paisaje de sus valores, de sus sentimientos. El paisaje, por tanto, nos presenta el mundo como es, pero es también, a su vez, una construcción, una composición de este mundo, una forma de ver-de mirar-el mundo (p. 193).

El paisaje natural es esencial para la fundamentación del paisaje cultural. El primero proporciona materiales y elementos, en tanto que el segundo es moldeado como parte de la vivencia cultural. Al iniciarse procesos adaptativos, simultáneamente se genera una transformación que conlleva rasgos de producción natural para sacar un beneficio. Al sumarse la adaptación y la transformación, se presenta una reacción lógica llamada producción que es transversal a todos los ámbitos de la experiencia humana, ya sean económicos, sociales, políticos y culturales, sin olvidar que para ejercer la producción se debe tener en cuenta, como eje central, la interacción entre el ser humano y el paisaje, interacción que va ligada entonces a procesos de identidad cultural.

\section{Metodología}

Fundamentar una investigación donde se muestre el impacto humano sobre el medio conlleva plantear una metodología de estudio acorde a las prácticas de las ciencias sociales. Debido a que se tuvieron en cuenta las expresiones y los argumentos del poblador de La Mojana, la interpretación por medio de un análisis significativo generó gran cantidad de información, dándole cuerpo a este trabajo. El estudio siguió el método de investigación cualitativo, cuya estructura conceptual y metodológica prioriza la comprensión del fenómeno estudiado desde la perspectiva de los participantes. Tal método genera puntos de vista locales a partir de experiencias directas, de interacción y participación, de trabajos de campo, de observación de comportamientos, de mensajes e ideas percibidas.

El tipo de investigación del que se dispone dentro de los esquemas del enfoque cualitativo es la investigación etnográfica, entendida por Pujadas (2010) como,

el proceso de adquisición del conocimiento sobre una determinada realidad sociocultural a partir de la aplicación de un conjunto de técnicas de campo y [...] entendida como producto, es decir, como el resultado de la elaboración e interpretación que el antropólogo hace del conocimiento adquirido (p. 12).

Por medio de este tipo de investigación se buscó abordar y definir grupos humanos, teniendo en cuenta sus costumbres, estilos de vida y cultura en general. Esta forma de hacer investigación permite recolectar información bastante completa, que en este caso particular conduce al reconocimiento de procesos adaptativos y de transformación del medio dentro de la relación hombre-medio en La Mojana sucreña. Al respecto del papel que desempeña el investigador etnógrafo, Atkinson y Hammersley 
(1983), anotan:

El etnógrafo participa, al descubierto o encubiertamente, en la vida diaria de las personas durante un amplio periodo de tiempo, mirando lo que sucede, escuchando lo que se dice, haciendo preguntas; recogiendo en realidad cualquier dato del que se disponga para arrojar luz sobre los problemas por los que está preocupado (p. 2).

En suma, la investigación etnográfica es una práctica reflexiva donde el investigador construye el carácter de una cultura desde sus visiones y reflexiones.

Para el desarrollo del trabajo de campo se realizaron observaciones directas y participantes, conversaciones, entrevistas abiertas, cuestionarios (hablar con las personas, preguntar, escuchar sus comentarios y obtener información escrita) y consulta de fuentes documentales. Asimismo, también fue necesario visitar varias veces La Mojana, percibir su entorno, visualizar el paisaje, anotar cada una de las manifestaciones culturales y su relación con el ambiente.

Los métodos de investigación aplicados en este trabajo dieron como resultado una serie de temas y subtemas que veremos a continuación y que reflejaron en los habitantes de La Mojana sucreña comportamientos de vida sumidos en el convivir, compartir y supervivir.

\section{Resultados}

\section{La cultura Anfibia y el empoderamiento sobre su medio ambiente}

a Del paisaje: Del estudio de campo, de lecturas textuales, de la revisión de imágenes y videos, de referencias explícitas por personas que han estudiado la región, y de un sinnúmero de informes y artículos alusivos a La Mojana sucreña, se puede concluir que su paisaje posee una gran riqueza. El manifiesto de variedad es latente, reconociéndose una nítida condición silvestre en su flora, fauna, fuentes hídricas y suelos, elementos omnipresentes tanto en los espacios rurales como en las edificaciones urbanas.

Tal riqueza también se evidencia en las viviendas que reflejan el sentir y condición de sus habitantes, en el hermoso colorido del amanecer y el atardecer, en la inundación y la sequía, en los terraplenes y camellones (algunos de origen Zenú, otros construidos actualmente para la intercomunicación y el regadío), en el ambiente paisajístico propio del festejo, en el vistoso colorido de la vestimenta de las personas, en las canoas y las chalupas, y demás expresiones que logran conciliar la exuberancia natural y cultural de la región.

El paisaje de esta cultura ribereña refleja sus condiciones económicas (riqueza, pobreza, miseria), el hato ganadero, el cultivo diverso, las faenas de pesca, las maneras de obtener el sustento, el prototipo de la mujer y hombre mojanero, entre otros aspectos de la cultura. En entrevista a los pobladores de La Mojana sucreña sobre cómo perciben el paisaje, estos responden: «Esto es un paraíso, por la tranquilidad y variedad de cosas que nos brindan para las comidas». Y al preguntarles sobre por qué ese paisaje les cambia por ciertas épocas del año, respondieron que,

nos cambia todo en el invierno (...) se necesita la lluvia, que además de ser una bendición, nos beneficiamos de ellas sobre todo en el cultivo de arroz, pero si son fuerte estas lluvias nos perjudicamos, pero nos adaptamos a ella. 
Queda claro entonces que el ser humano hace uso de valores culturales para sobrevivir, y que el paisaje natural, además de manifestar expresiones visiblemente materiales, va cargado de un simbolismo que para los pobladores de una región particular se traduce en rasgos culturales muy propios. En el caso de la cultura de La Mojana, las inundaciones y las sequías reflejan modos de vida estacionales, circunstancia que los ha hecho merecedores del rótulo de cultura anfibia.

b La llamada cultura anfibia: Los pobladores de la Mojana poseen rasgos culturales tan propios y particulares que les ha merecido el título de cultura anfibia, ya que su relación de dependencia, de amor y odio con el agua, les ha permitido elaborar todo un universo de significado alrededor de ella. O por lo menos así queda evidenciado en la entrevista realizada a un poblador de la región y estudioso del tema, donde explica:

Lo de cultura anfibia es porque les toca, aunque manifiestan poder sobrevivir en ambas épocas (sequía - lluvia), reconocen las lluvias como una amenaza, que algunos desean irse a otro sitio con otras condiciones, pero no tienen a dónde ni con qué. La comarca rural es la que más padece y es la que más desea irse a vivir a otro lugar, pero no encuentran como hacerlo.

En cambio, otro de los pobladores expresa:

Nos hacemos al lugar por razones familiares, de trabajo, por la tranquilidad, por gusto propio, por ser nuestra tierra, esa que nos ha albergado en su seno y que es muy difícil que la dejemos muy a pesar de las incomodidades que se den el campo y en el municipio.

Lo anterior refleja que la cultura anfibia es producto de un proceso de arraigo, de amor filial hacia su territorio y a quienes alberga. Pero esta realidad se yuxtapone a otra, según la cual al poblador le toca vivir las circunstancias del ambiente que los somete y que en algunas ocasiones los hace desear irse para no soportar la inundación. Sin embargo, la gran mayoría saca provecho de cada una de las condiciones de su medio. Por ejemplo, vivir en épocas de inundación — cuando se prioriza la faena de la pesca que caracteriza a la población - se transforma en un aspecto cultural que fortalece el sistema de relaciones y aspectos sociales encaminados al valor de la subsistencia, como lo son la economía familiar y la riqueza alimentaria. La cultura anfibia representa métodos de vida adaptativos dirigidos a la supervivencia de una población única. Sus integrantes hacen uso de diversos mecanismos de apropiación del entorno en diferentes épocas del año, siendo solidarios entre sí para conseguirlo. Son una familia unida, como ellos lo manifiestan, pues les toca compartir en comunidad si quieren superar los desafíos que el medio ambiente les plantea en cualquier época del año.

c De los procesos de adaptación: La adaptación es inherente a todo ser vivo, es una respuesta de supervivencia al medio. La adaptación es incentivada por el deseo de salir adelante, por la necesidad de buscar mecanismos de sobrevivencia en el ambiente, aprovechando lo que este le brinde en diferentes épocas del año.

Muchas personas se adaptan a un medio según su manera de pensar, donde la inteligencia, la memoria y la imaginación incorporadas a los elementos de la cultura, se despliegan y desarrollan y pueden crear a su vez nuevos elementos culturales. En otras palabras, poniendo de lleno todas las capacidades mentales a una cultura, se logra la adaptación a esta.

Los pobladores de La Mojana sucreña no solo se adaptan al medio ambiente o al paisaje, sino que 
hacen un gran sobre ellos. Ante las inundaciones, por ejemplo, el habitante de La Mojana sucreña pone en juego su cultura anfibia, pues debe corporalmente soportar la inundación y la sequía, debe tocar tierra firme en cierta época y nadar o vivir arriba de objetos en épocas de crecientes, como lo muestra la Figura 3. esfuerzo por cambiar el impacto que este medio tiene.

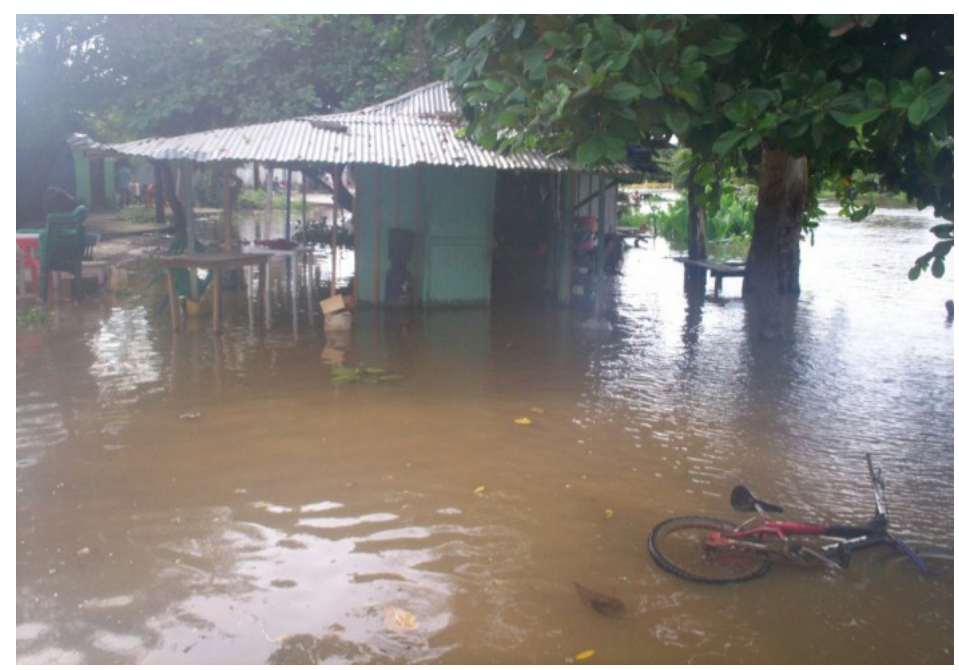

Figura 3. El drama de La Mojana. Fuente. Fotografía de archivo (2010)

Las condiciones corporales de los habitantes de La Mojana reflejan sus capacidades para lograr su adaptación. Cuando se les pregunta sobre las estrategias de adaptación a las inundaciones que han desarrollado, los pobladores responden:

Tenemos el hábito de guardar los alimentos, sacar el ganado, recoger cosechas, buscar partes altas, etc.; la población de la cabecera municipal solamente espera, hacen sus ahorros, buscan territorios altos, aterran sus casas, hacen tambos y en el extremo de los casos buscan otro sitio fuera del municipio para poder sobrevivir.

Como se puede apreciar en el testimonio anterior, la adaptación permite la preparación ante las circunstancias que brinda el ambiente, ya que tanto en la zona rural como en la urbana se encuentran mecanismos adaptativos para sobrevivir. Al preguntárseles que si padecen ante las inundaciones, los habitantes responden de manera afirmativa. Sin embargo, al preguntarles por las razones por las que soportan las inundaciones, algunos responden: «por el arraigo y sentido de pertenencia hacia nuestra tierra, por estar amañados o acostumbrados y tenemos la esperanza de que todo va a mejorar y que nos toca adaptarnos pues tenemos lo muestro aquí»». Mientras que otros manifiestan:

Nos hacemos al lugar por razones familiares, de trabajo, por la tranquilidad, por gusto propio, por ser nuestra tierra, esa que nos ha albergado en su seno y que es muy difícil que la dejemos muy a pesar de las incomodidades que se den en el campo y en los lugares.

La adaptación juega un papel importante, pero se acrecienta por el amor que los habitantes de La Mojana tienen por todo lo que les circunda. Es claro que las inundaciones representan un problema, pero a pesar de eso se debe seguir adelante, no se pueden quedar a que el paisaje y sus manifestaciones 
hagan de las suyas; es sobrevivir o morir.

La cultura anfibia es una adaptación constante ante los ciclos de inundación y sequía, que se traducen en una identidad cultural fuerte con características muy marcadas. En la Figura 4 se muestra cómo las personas tienden a realizar actividades propias del momento climático que transcurre. Entender que hay que afrontar las inundaciones, sea anualmente o por periodos de tiempo, es considerable para algunos habitantes; y creer que existe una solución para estas, es creencia de otros muchos. Sin embargo, mientras esto último ocurre, es necesario luchar en la transformación del medio para poder habitarlo.

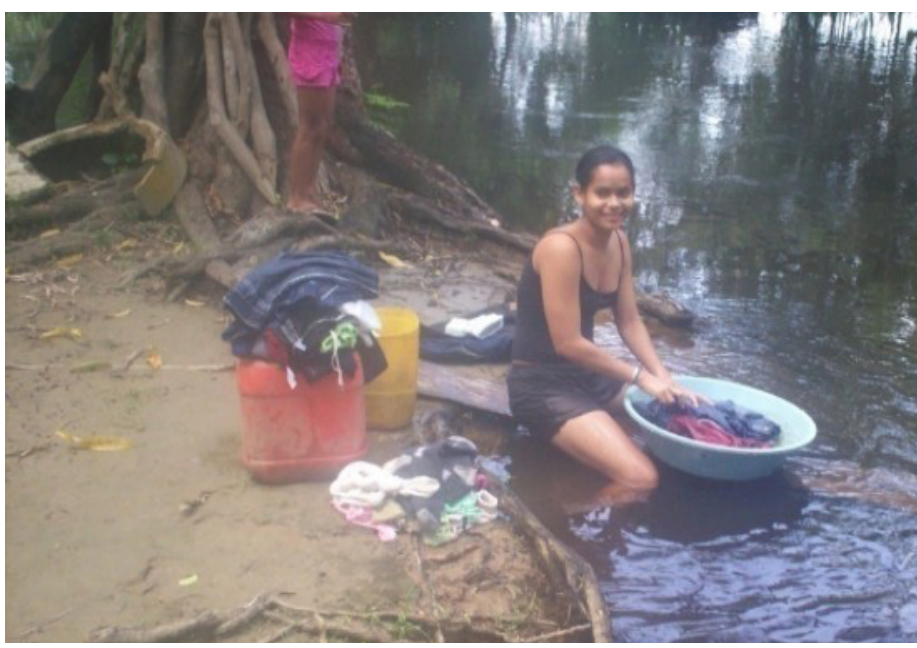

Figura 4. Lavando en La Mojana. Fotografía de archivo (2010)

Cada habitante de La Mojana sucreña es estimado por las cosas que hace, por su manera de sentir y de pensar; de él depende su comunidad, pues está en cada miembro la competencia de adaptación e integración. Varios de sus pobladores no logran adaptarse y se marchan, pero muchos sí han conseguido perdurar.

Las formas de adaptación económica se relacionan con sus actividades de producción, sobre todo de tipo agropecuario. La tierra es su mejor factor de producción de cultivos estacionales, de sequía y de los que se pueden hacer cuando empiezan las lluvias, teniendo en cuenta que deben estar listos antes de que lleguen las inundaciones para no tener pérdidas.

La ganadería, al igual que la agricultura, debe considerar la época del año, pues por las inundaciones mueren muchos animales. Por este motivo deben trasladarlos muy lejos a tierras altas. Por ello el habitante de La Mojana sucreña se adapta a no percibir ganancias ni productos de la actividad ganadera, circunstancia que lo obliga a buscar otras formas de subsistencia económica y el cambio de su dieta alimenticia. Ante esto, los pobladores afirman:

Las lluvias son un proceso normal que ayuda a los cultivos, pastos, el ganado y la obtención de agua, sin embargo, lo malo es cuando estas aumentan pues se dañan las vías, los caminos y se vienen las inundaciones, todo cambia.

A nivel social, el habitante de La Mojana sucreña se adapta a los procesos de vida naturales y culturales; sus viviendas, modos de transporte, educación, salud, recreación, religiosidad, entre otros, están supeditados también a las épocas de lluvia y sequía. Es tal el nivel de adaptación que en muchos casos las viviendas sufren transformaciones en las inundaciones. Como se puede apreciar 
en la Figura 5, a las casas se les adaptan los "tambos", que son andamios rústicos de madera a una altura considerable y que sirven para no mojarse y poder desplazarse por el hogar. De igual forma se modifican los mecanismos de desplazamiento y transporte en el territorio, pues de andar a pie, en bicicleta o moto, pasan a usar canoas. Al respecto, manifiesta un poblador:

Las inundaciones nos tratan muy duro, en la sequía hay mejor forma de transportarse, hay mototaxismo, los productos bajan de precio, hay mejor salud, pues no hay mosquitos, ni enfermedades producidas por las lluvias, y por la tranquilidad de no padecer problemas.

Y es que hasta la actividad escolar debe adaptarse a estas variaciones. Los calendarios escolares deben modificarse, se trabaja en horarios especiales y se inicia el año escolar desde los primeros días del año, avanzando en la programación de estudio antes de que inicien las lluvias.

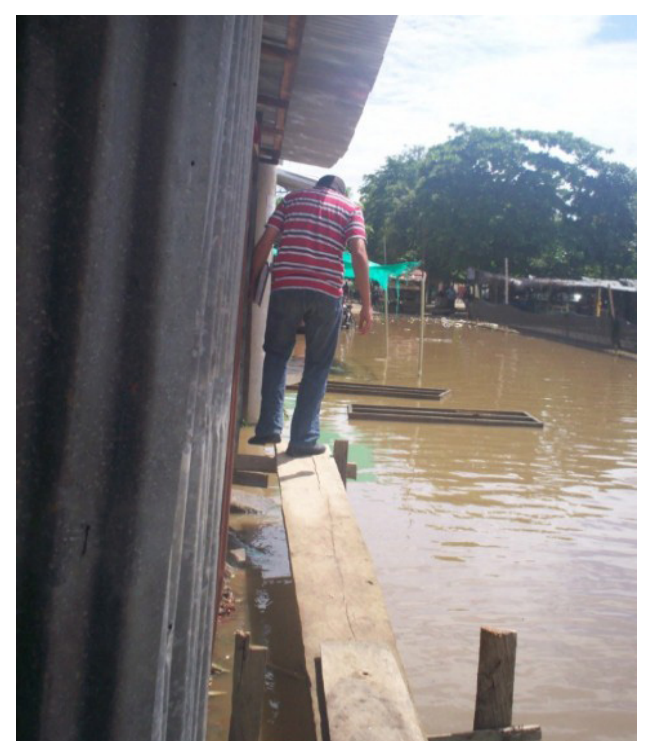

Figura 5. Caminando sobre tambos. Fotografia de archivo (2010)

d Transformación del paisaje por parte de los habitantes: Con la adaptación se tiene que seguir un proceso de transformación del paisaje, entendido como hacer cambiar de forma o naturaleza algún terreno. La transformación va entretejida con unos procesos de reconocimiento, análisis, aceptación y adaptación.

Carl Sauer (1925), en su obra La morfología del paisaje, expone que el paisaje natural está siendo sometido a transformaciones por la mano del hombre, siendo este el último y más importante factor morfológico. El ser humano, en su transformación, puede utilizar la naturaleza en todas sus formas, alterándola y muchas veces destruyéndola. Cada generación se apropia de las técnicas que la preceden y las mejora. Por ejemplo, es posible transformar el estilo de vivienda para prevenir el desastre ante una inundación o transformar una dieta alimentaria dependiendo de la época climática; del mismo modo, la actividad trashumante del ganado también transforma el paisaje, al igual que lo hace el cultivo estacional, o el hacer fiestas y eventos de acuerdo a la época.

Otro modo de transformación del paisaje es abonar o aterrar las ciénagas para el aprovechamiento en el cultivo, construir puentes, hacer terraplenes para transitar y encauzar el agua. Además de esto está el hecho de viajar en canoas, motos y bicicletas según la época climática, o ubicar las 
viviendas o sitios institucionales sobre terrenos altos para impedir que se inunden. Estas y muchas otras manifestaciones más son producto de la transformación de un medio físico, fenómenos que se seguirán viendo puesto que este proceso es evolutivo.

Trabajar con la mente puesta en la supervivencia es lo que caracteriza la transformación del paisaje en La Mojana sucreña. Actuar de un modo que depende de la época climática, donde de forma natural se transforma el paisaje cuando llegan las lluvias y con ella las inundaciones, permite que el habitante de la región también transforme ese ambiente de acuerdo a la época del año.

La transformación, además de ser una opción de la humanidad para sobrevivir, se ha convertido en La Mojana sucreña en un proceso cíclico de épocas de lluvias y sequías. Viéndolo de esta forma parece normal, pero lo que en La Mojana sucreña se evidencia casi siempre son inundaciones que deben ser superadas con los mecanismos de transformación con que cuentan sus habitantes.

e Interacción Ser Humano - Medio Ambiente: Lo relatado hasta el momento aporta evidencia sobre la forma tan particular como los habitantes de La Mojana sucreña se apropian de su entorno. Recordemos que el paisaje se transforma por sus propias fuerzas y por las actividades del ser humano producto de su experiencia. Desde el ámbito humano, este somete al medio ambiente a procesos de adaptación y transformación, en este estudio investigativo se ha tratado de vincular estos procesos con la cultura anfibia.

La interacción del ser humano con su medio lo convierte en su poseedor. Este le garantiza su supervivencia. Con el simple hecho de estar en un medio, natural o artificial, el ser humano le imprime sus rasgos y características particulares.

En La Mojana sucreña sus habitantes interactúan con el entorno bajo ciertas metas y propósitos de sobrevivencia. Algunos académicos, como Fals Borda, le asignan una distinción: la cultura anfibia, la cual se vivifica bajo el fundamento del querer de un pueblo en seguir adelante, imprimiendo sus cualidades a las imposiciones que el medio le determina. Al respecto, los habitantes de La Mojana observan:

No nos vamos por la costumbre, por estar amañados, por las riquezas naturales o porque no tenemos a dónde irnos. Allá afuera no hay donde vivir, sería ir a aventurar (...) Es un sentir que se manifiesta no con el solo hecho de nacer y vivir allí, y tener una familia; es por pertenencia, por querer, por arraigo, por las riquezas naturales, porque somos una gran familia, la convivencia y por ser así como es.

Es notable la gran relación del ser humano con su medio ambiente. Es por así decirlo, una identidad cultural muy marcada.

Los habitantes de La Mojana sucreña interactúan con el medio aun sabiendo que sufrirán ciertos percances que les impone la naturaleza (inundaciones). Sin embargo, ello es un reto cíclico que se supera con habilidad y actitud. El medio y las condiciones climáticas no condicionan totalmente la vida; el ser humano fluye y se adapta para vivir en él. La Mojana sucreña es el claro reflejo de la adaptación que realizan sus habitantes en ese medio, se adhieren a sus circunstancias y van buscando un moldeamiento para la supervivencia. Lo mejor es que esa apropiación de su entorno los lleva a la producción constante, y de allí a sus beneficios individuales y sociales.

La interacción hombre-medio se asemeja a un ciclo que inicia con la interrelación del ser humano con el paisaje bajo acciones propias del contacto. Es un accionar que comienza con el reconocimiento que hace el poblador a su entorno, no quedando allí este se adapta generando procesos de transformación. Ser competente en el medio suscita actos de producción que con la mayúscula interacción y vital 
información van a moldear a una gran cultura: la cultura Mojana. Traducido desde al actor humano en su medio histórico - geográfico como cultura anfibia (ver Figura 6).

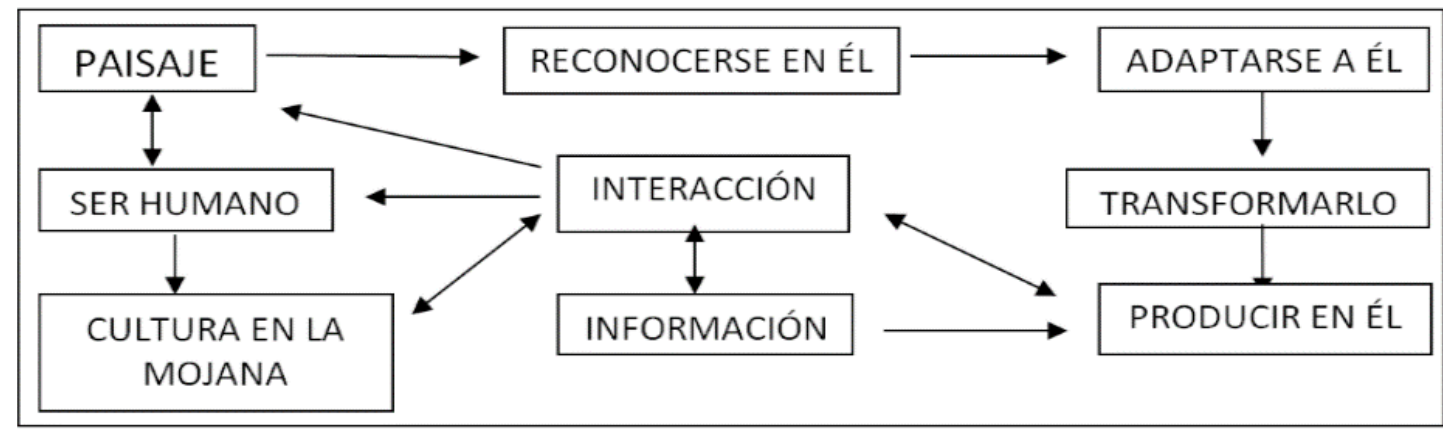

Figura 6. Esquema de la interacción hombre-medio en La Mojana sucreña.

f Percepción de los habitantes hacia su entorno: Los procesos de investigación llevados a cabo en La Mojana sucreña dan cuenta de las formas de apreciar el entorno que tienen los habitantes de la región. Son ellos quienes afirman o niegan ciertas apreciaciones. La percepción de su hábitat es muy valiosa; es esa población a la que hay que poner de manifiesto, pues sus valoraciones dan luces para entender sus procesos de adaptación y producción en el medio. Al respecto de las lluvias y las sequías, los habitantes de La Mojana tienen las siguientes percepciones:

Las lluvias son un proceso normal que ayuda a los cultivos, pastos y la obtención de agua, sin embargo, lo malo es cuando estas aumentan pues se dañan las vías, los caminos y puede llevar a las inundaciones. La sequía es una época buena para la recuperación de pastos y el transporte terrestre pero cuando es muy fuerte es mala para el cultivo y para la obtención del agua para los quehaceres (...) Muchas veces en sequía el agua tiene que ser obtenida a varios kilómetros en pozos artesanales.

Ahora bien, cuando las lluvias aumentan y comienzan las inundaciones, la percepción del poblador de La Mojana tiende a ser esta:

Cuando se inunda la región, se presentan muchas destrucciones en cultivos y en general pérdidas económicas que conllevan la escasez de alimentos, parálisis comercial, destrucción de viviendas, entre otros; pero lo que más llama la atención es el padecimiento, las enfermedades y la tristeza, pues no se puede comparar con la época de sequía donde el ambiente es de prosperidad y alegría.

Las percepciones que se tienen de las inundaciones suelen ser muy pesimistas, por lo que cada poblador debe ser asertivo y poner en funcionamiento las habilidades desarrolladas de adaptación al medio que caracteriza a los integrantes de este territorio. Todo queda plasmado en la siguiente frase de uno de sus habitantes: «Las inundaciones no tienen solución, no ve que es algo natural, como una ley de la propia naturaleza, qué podemos hacer... hay que vivir».

Aunque la percepción negativa no solo es por las inundaciones. Los pobladores también manifiestan que además de estas, hay otros los problemas que los aquejan:

La Mojana está atrasada por las situaciones de las inundaciones, pero también por el poco desarrollo, las malas vías de transporte, el poco progreso, el desempleo, la politiquería, la falta de mercado, 
carencia de recursos económicos, la escasez de oportunidades, entre otros.

Es evidente que el olvido estatal y la poca proyección de la población hacen que sus condiciones de vida sean bajas. Sin embargo, también es cierto que las inundaciones interfieren en su vida normal. Son las malas acciones humanas junto con las inundaciones las que acechan el desarrollo, pero se ha podido sobrevivir con el único valor perenne, el esfuerzo, basado en el fuerte arraigo cultural de los habitantes de La Mojana a su territorio.

Indagados sobre el lugar en el que les gustaría vivir diferente a La Mojana, fue común la respuesta: «Sincelejo, Cartagena, Barranquilla, Montería, Medellín y municipios aledaños a estos», tal como lo muestra la Figura 7.

Como razones para elegir estos municipios, los pobladores en edad juvenil o adulta adujeron las siguientes: «para tener mejor empleo, buenas condiciones de vida, mejores oportunidades de estudio o porque sus cultivos y crías de animales no están amenazados». Contrario a ello, la gran mayoría de los adultos mayores prefieren no salir de su territorio.

La ciudad de Sincelejo es la que posee mayor preferencia, quizás por ser la capital del departamento donde se ubica la subregión de La Mojana. Alternativamente, algunos entrevistados manifestaron tener familiares viviendo en esa ciudad o que es el lugar donde reciben los servicios de salud, pues están afiliados con la entidad territorial del departamento, lo cual facilita su atención.

Sin embargo, las apreciaciones anteriores están supeditadas a un grupo pequeño de personas, debido a que muchos manifestaban que no les interesaba salir de la región, sobre todo los adultos. Los jóvenes tienen la visión de salir, pero expresan que les costaría mucho pues su tierra les haría mucha falta.

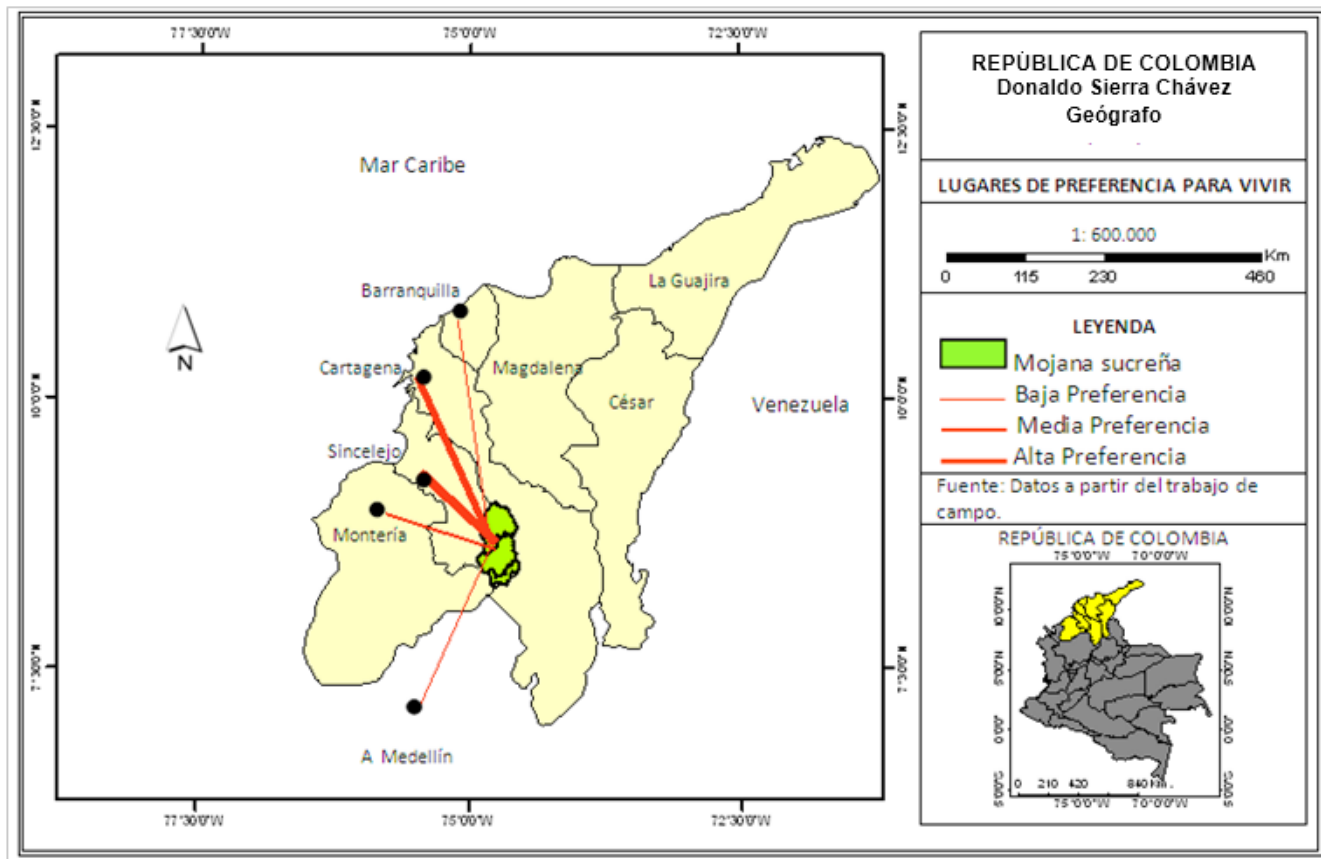

Figura 7. Lugares de preferencia para vivir. (Elaboración del autor a partir de datos del IGAC)

g Discusión: Con todo lo anterior, sin apartarse de la realidad vivida en esta investigación, tras varios trabajos de campo en épocas climáticas distintas (lluvia y sequía) y luego de observar detalladamente el paisaje, charlar con la comunidad y analizar entrevistas escritas, se puede deducir 
que La Mojana es tierra de contrastes. Se aprecia un entorno bello con gente linda, pero también se observa un medio hostil que debe ser enfrentado por sus habitantes para convertirlo en apacible.

La Mojana representa mucho para su pueblo y el paisaje constituye parte vital de la existencia de todas sus comunidades. Las lluvias moderadas suelen ser ayuda para el equilibrio de sus vidas, pero las exageradas precipitaciones las llevan a adoptar un modo de vida anfibio. Según Millán (2004):

La mirada que le brinden las personas a un lugar se fundamenta cuando se acepta como tal, cuando se dan cuenta de que este se integra a las condiciones que le imponen los habitantes. La Mojana es percibida por sus pobladores con o sin inundaciones, con o sin transformaciones, y esta percepción la acompañan con su diario vivir y en su paisaje (p. 142).

La apreciación de Millán es crucial gracias a que denota las posibilidades de interpretar el entorno desde la mirada del visitante-investigador. Pero aunque no sea una tarea fácil, cabe recordar que la mirada de aquel debe estar supeditada a lo que en realidad viven sus habitantes, porque con el solo hecho de aceptar e integrarse a lo que muestre el medio y brindan sus pobladores, se generará una buena expectativa.

Asimismo, de la cita de Millán se colige que la situación que vive el poblador es diferente de la apreciación que puede hacer el visitante. Apreciar la profunda compenetración de una comunidad con su entorno de vida no es tarea fácil. La aceptación de las circunstancias que le propone el entorno es para el habitante de La Mojana el contexto donde se constituye el valor que sus habitantes le dan a su medio ambiente, no importando en qué época climática del año estén, ni en qué situación se encuentren.

La opinión de Millán también resulta relevante para comprender que el habitante de La Mojana acepta su medio natural. Tal aceptación encuentra soporte en la integración del habitante con su medio a partir de su adaptación y transformación. Al charlar con la población, se encuentra que sí tienen ciertas apreciaciones particulares en cuanto a las épocas de sequía e inundación, lo cual es un principio clave en la aceptación de su medio.

En La Mojana se expresan condiciones de vida sin importar la época del año. Los habitantes de la zona muestran su cultura tal cual es, son receptivos y dispuestos al trabajo. Pero en la época de las inundaciones el medio exige de las personas grandes esfuerzos para poder sobrevivir, pues estas condiciones ponen a la población al límite de sus posibilidades de subsistencia en muchas ocasiones.

Ahora, transcurrido gran parte de este escrito y para dar un efecto conclusivo a todo lo abordado, surge un interrogante: ¿Cómo ha sido el proceso de transformación del paisaje por parte de los habitantes de La Mojana sucreña? Si bien la respuesta parece sencilla y quizás ya haya sido expresada, la historia de la región es el reflejo de cómo se ha dado el proceso. Desde el poblamiento nativo, el indígena Zenú aplicó muchas técnicas y herramientas que el poblador actual también aplica. Así lo aseguran Plazas, Falchetti, Sáenz, \& Archila (1993): «Estos suelos tan difícilmente manejables en el presente fueron explotados agrícolamente con intensidad por los pobladores prehispánicos, quienes con un sistema hidráulico controlaron las inundaciones y mejoraron el drenaje de los suelos» (p. 43).

Como se aprecia en la cita anterior, la transformación del medio para poder sobrevivir implicó un arduo trabajo, tanto en el pasado como ahora. Es cierto que apremian el progreso, el desarrollo, el bienestar; aunque muchas veces la naturaleza se ensaña con la población, pero igualmente las ganas de salir adelante persisten.

Toda civilización crea un impacto en su medio y lo hace transformando su entorno de la mejor manera que puede su entorno. Entiéndase que lo que se busca es mantenerse allí. Con la transformación 
del paisaje en La Mojana sucreña se impregna el valor humano, que bajo ciertas actividades adiciona su poder hacia el medio. La cultura anfibia es el producto de esa relación ser humano-medio ambiente.

Fals Borda (2002a), ha sido uno de los más grandes estudiosos de la cultura anfibia de La Mojana. El autor reconoce una gran manifestación humana sobre el medio con expresiones como la siguiente:

La cultura anfibia explica el poblamiento lineal de las laderas, caseríos y muchos pueblos riberanos, así como su persistencia: son aldeas en línea construidas en los barrancos secos y estrechos que bordean las corrientes fluviales. Los lotes resultantes en que se construyen las casas no pueden ser muy largos porque al fondo se encuentran las ciénagas o las cercas de alguna gran hacienda (p. 23).

Es de resaltar la preferencia de los pobladores por la cercanía a las fuentes de agua. Se puede evidenciar aquí otra connotación de la cultura anfibia ya que el agua le brinda condiciones "óptimas" de subsistencia. Según Fals Borda (2002b):

La articulación de lo geográfico con lo histórico, lo social y lo económico se registraba localmente en comunidades denominadas laderas, que son viviendas dispersas en forma lineal en barrancos a lo largo de corrientes de agua, en caseríos y en pueblos de mayor tamaño igualmente aferrados al agua, donde se desarrolla la vida afectiva, cultural, productiva y reproductiva del hombre ribereño (p. 21).

La cultura anfibia se asienta sobre lugares cercanos a fuentes de agua (haciendo un reconociendo en el lugar se observa esta situación), la gran parte de la población lo hace para asegurar el sustento. Ahora bien si se analiza esta situación queda en evidencia que el agua genera recursos de supervivencia vitales para los pobladores, pero ellos al ubicarse cerca de estas fuentes de agua deben buscar formas de adaptación para sopesar las inundaciones, es decir, establecerse en un sitio aun sabiendo que se van a inundar, ahí está la gran virtud de supervivencia del habitante de La Mojana.

No se puede desconocer el gran trabajo que los habitantes de La Mojana han hecho sobre su territorio, pues desde tiempos históricos han moldeado el paisaje. Pero más fuerte y evidente es el arraigo hacia su región y son claras las manifestaciones de apego a lo propio: es la costumbre de estar en un lugar que les brinda todo, pero que a la vez les quita mucho por las inclemencias climáticas.

\section{Conclusiones}

La investigación realizada en La Mojana sucreña da como resultado formas diferentes de observar su paisaje, su cultura, su adaptación, transformación y producción en el medio, y las maneras como se presenta el desarrollo y su prospectiva territorial. Además de lo anterior y centrados en el proceso investigativo fundamentado en las técnicas de estudio etnográfico y de la cultura, se puede concluir que las adaptaciones de los habitantes de La Mojana son el producto de muchos años de arraigo y compenetración con su medio físico y humano, que al transformarlo asegura el mínimo de supervivencia ante la emergencia de las lluvias e inundaciones.

Estar en La Mojana sucreña, vivenciar todo lo que existe en ella, nutre las ideas y supera las expectativas de cómo los habitantes se compenetran con su hábitat. Las respuestas de los pobladores en las entrevistas realizadas son apenas un reflejo de lo que puede percibir, sentir y expresar el habitante de La Mojana. Sus expresiones esbozan un sentimiento cultural muy apegado a su territorio.

La riqueza hídrica de La Mojana conlleva patrones de asentamiento cerca de las fuentes de agua, pues esta les permite la obtención de alimentos y aprovechamientos en diferentes actividades. Sin embargo, son muy propensos a las inundaciones por su cercanía a estos cursos fluviales. 
Desde el pasado, el ejemplo de supervivencia de los indígenas Zenú en estas tierras de La Mojana da fe de que la adaptación al medio es primordial en los procesos de asentamiento y progreso de las comunidades. En la actualidad sus pobladores luchan para poder seguir adaptándose y transforman un medio que les brinda circunstancias adversas. El poblador de La Mojana se convierte en un escultor de su paisaje, siendo la cultura, en su modo de vida, la que le imprime rasgos de supervivencia, característica incuestionable de una cultura anfibia. Se reconoce el paisaje como parte de su vida, son integrantes de un territorio que les brinda lo necesario para la supervivencia. Creen en su tierra, se identifican con ella y muchos de ellos no ven otro modo de vida diferente que vivir cerca de las fuentes de agua que les brindan el sustento en temporadas de y lluvias y sequías.

Para los pobladores de La Mojana sucreña la supervivencia es más llevadera en esta región que en la ciudad. Para ellos las fuentes de agua garantizan el alimento, seguridad que no atisban en la ciudad. Sin embrago, parte de la población ve la necesidad de salir ante las inundaciones para buscar otros sitios mejores para la vida.

A pesar de que los habitantes padecen una situación difícil producto de las inundaciones, ya saben cómo sortear este impase. Por ello prefieren mantenerse en estas circunstancias adversas antes que aventurarse en otro territorio donde no poseen el conocimiento suficiente de su paisaje y no encuentran las riquezas de recursos que puede brindar La Mojana.

La evolución cultural del habitante de La Mojana hace que este fortalezca la dinámica de transformación al medio. Dependen de ello las actividades que desarrollen sus habitantes ante cualquier circunstancia que brinde el entorno, es decir, el desarrollo de su cultura es un producto de las labores cotidianas.

Además de su vínculo familiar, uno de los rasgos de identidad más relevantes de los habitantes de La Mojana sucreña es el arraigo con la cultura, es querer su "terruño" muy a pesar de vivir las inclemencias de las inundaciones. Muchos de ellos ven en sus coterráneos una familia, la gran familia Mojana.

La cultura de La Mojana, se reconoce como un estilo de vida que desafía las inundaciones. Por esta circunstancia se considera como una cultura anfibia en la que sus habitantes ponen en práctica criterios de transformación y adaptación a su medio. Lo que buscan es asegurar la vida. Por ello su población enfrenta los problemas y aviva sus esperanzas bajo la coraza del sentir su territorio.

En La Mojana es notable la compenetración del ser humano con su paisaje. Es allí donde se fortalece su habitante con la lucha del diario vivir, hecho que va haciendo eco en el transcurrir del tiempo. Una cualidad del habitante de La Mojana es la paciencia, pues sortea el impacto del medio con gran entereza al adaptarse a las condiciones y tiempos que le impone cada inundación, gracias al amor que se tiene hacia su tierra. Aunque las inundaciones suelen ser cíclicas, el habitante de la cultura anfibia no se desespera y pone de manifiesto sus facultades adaptativas al medio acuático y terrestre.

La adaptación y la transformación del ambiente, además de ser una opción de los seres humanos para sobrevivir, en La Mojana sucreña se han convertido en un proceso cíclico de épocas de lluvias y sequías. Nótese esto como normal, pero lo que sucede es que el poblador no logra calcular la dimensión de las inundaciones, lo que supone una adaptación muy rápida. Esto solo lo puede hacer una cultura que conoce el desafío al que es sometido.

Todo gira alrededor de lo que puede hacer el agua con el medio ambiente, realidad en la que se incluye al ser humano. Sin embargo, esta apreciación un poco determinista es solventada con la inventiva y el deseo de sacar adelante la vida de las comunidades.

Un flagelo muy notorio en La Mojana sucreña es la pobreza, fenómeno que resulta visiblemente agravado por las inundaciones. La Mojana es una comunidad que se dedica a actividades agrícolas, 
ganaderas y pesqueras, pero que se supeditan a la avanzada de las inundaciones. Cultivar y criar animales se convierte en todo un reto porque no se puede predecir una inundación y de suceder se podría perder todo. Esto ha pasado muchas veces.

Para posteriores estudios es necesario tener en cuenta las referencias de la prospectiva territorial, pues esta brinda pautas y apreciaciones básicas hacia el futuro imaginado de La Mojana sucreña. Hay que apreciar mucho más la voz del pueblo, toda vez que sus ideas pueden sacar adelantes a esta región. De igual forma se deben crear mejores e integradores modelos sociales con un fuerte y decidido apoyo gubernamental.

Finalmente, no se puede dejar de lado la participación activa de los pobladores en el proceso de generación de datos propios de la investigación y como fuente fidedigna de información, aspectos cruciales que dieron fundamento a la consecución de los objetivos propuestos. Conocer de la cultura anfibia dentro de la adaptación, transformación y producción en su medio genera ideas que se asumen como propias de una cultura que lucha y busca, entre sus formas de vida, la adecuación para la supervivencia.

\section{Referencias}

Atkinson, P., \& Hammersley, M. (1983). Etnografía: Métodos de investigación. Barcelona: Paidós. Barfield, T. (Ed.). (2007). Diccionario de Antropología. México: Siglo XXI Editores.

Fals B, O. (2002a). Historia Doble de la Costa Atlántica 1: Mompox y Loba. Bogotá: El Ancora Editores.

Fals B, O. (2002b). Historia Doble de la Costa Atlántica 3: Resistencia en el San Jorge. Bogotá: El Ancora Editores.

Harris, M. (1968). El desarrollo de la teoría cultural. Nueva York: Crowell.

Millán E, M. (2004). La geografía de la percepción: una metodología de análisis para el desarrollo rural. España: Escuela de turismo de Murcia.

Nanda, S. (1987). Antropología cultural: adaptaciones socioculturales. México: Grupo Editorial Iberoamérica.

Plazas, C., Falchetti, A. M., Sáenz, J., \& Archila, S. (1993). La sociedad hidráulica Zenú. Bogotá: Departamento Editorial Banco de la República.

Pujadas M, J. J. (2010). Etnografía. Barcelona: Editorial UOC.

Romero, J. (2008). Geografía Humana: Procesos, riesgos e incertidumbres en un mundo globalizado. Barcelona: Ariel.

Sauer, C. (1925). Morfología del paisaje. Universidad de California.

Tylor, E. (1976). Cultura Primitiva. Tomo 1. Madrid: Ayuso. 